NASA/TM-2003-212526

ARL-TR-2955
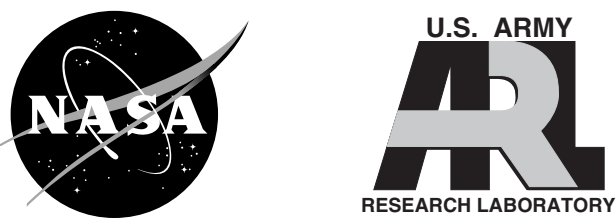

\title{
Application of a Bank of Kalman Filters for Aircraft Engine Fault Diagnostics
}

Takahisa Kobayashi

QSS Group, Inc., Cleveland, Ohio

Donald L. Simon

U.S. Army Research Laboratory, Glenn Research Center, Cleveland, Ohio 
Since its founding, NASA has been dedicated to the advancement of aeronautics and space science. The NASA Scientific and Technical Information (STI) Program Office plays a key part in helping NASA maintain this important role.

The NASA STI Program Office is operated by Langley Research Center, the Lead Center for NASA's scientific and technical information. The NASA STI Program Office provides access to the NASA STI Database, the largest collection of aeronautical and space science STI in the world. The Program Office is also NASA's institutional mechanism for disseminating the results of its research and development activities. These results are published by NASA in the NASA STI Report Series, which includes the following report types:

- $\quad$ TECHNICAL PUBLICATION. Reports of completed research or a major significant phase of research that present the results of NASA programs and include extensive data or theoretical analysis. Includes compilations of significant scientific and technical data and information deemed to be of continuing reference value. NASA's counterpart of peerreviewed formal professional papers but has less stringent limitations on manuscript length and extent of graphic presentations.

- TECHNICAL MEMORANDUM. Scientific and technical findings that are preliminary or of specialized interest, e.g., quick release reports, working papers, and bibliographies that contain minimal annotation. Does not contain extensive analysis.

- CONTRACTOR REPORT. Scientific and technical findings by NASA-sponsored contractors and grantees.
- CONFERENCE PUBLICATION. Collected papers from scientific and technical conferences, symposia, seminars, or other meetings sponsored or cosponsored by NASA.

- SPECIAL PUBLICATION. Scientific, technical, or historical information from NASA programs, projects, and missions, often concerned with subjects having substantial public interest.

- TECHNICAL TRANSLATION. Englishlanguage translations of foreign scientific and technical material pertinent to NASA's mission.

Specialized services that complement the STI Program Office's diverse offerings include creating custom thesauri, building customized databases, organizing and publishing research results ... even providing videos.

For more information about the NASA STI Program Office, see the following:

- Access the NASA STI Program Home Page at http://www.sti.nasa.gov

- E-mail your question via the Internet to help@sti.nasa.gov

- Fax your question to the NASA Access Help Desk at 301-621-0134

- Telephone the NASA Access Help Desk at 301-621-0390

- Write to:

NASA Access Help Desk

NASA Center for AeroSpace Information 7121 Standard Drive

Hanover, MD 21076 
NASA/TM-2003-212526

ARL-TR-2955
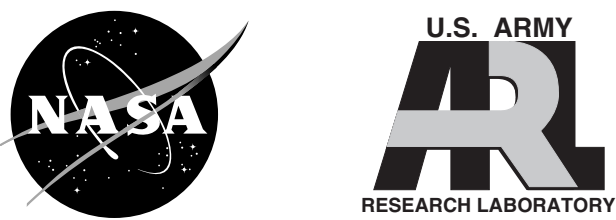

\section{Application of a Bank of Kalman Filters for Aircraft Engine Fault Diagnostics}

Takahisa Kobayashi

QSS Group, Inc., Cleveland, Ohio

Donald L. Simon

U.S. Army Research Laboratory, Glenn Research Center, Cleveland, Ohio

Prepared for the

Turbo Expo 2003

cosponsored by the American Society of Mechanical Engineers

and the International Gas Turbine Institute

Atlanta, Georgia, June 16-19, 2003

National Aeronautics and

Space Administration

Glenn Research Center 


\section{Acknowledgments}

This research was funded by the NASA Aviation Safety Program as a task under the Propulsion System Health Management Element.

Available from

NASA Center for Aerospace Information 7121 Standard Drive

Hanover, MD 21076
National Technical Information Service 5285 Port Royal Road Springfield, VA 22100

Available electronically at http:/ /gltrs.grc.nasa.gov 


\title{
APPLICATION OF A BANK OF KALMAN FILTERS FOR AIRCRAFT ENGINE FAULT DIAGNOSTICS
}

\author{
Takahisa Kobayashi \\ QSS Group, Inc. \\ Cleveland, Ohio 44135 \\ Email: Takahisa.Kobayashi@grc.nasa.gov \\ Donald L. Simon \\ U.S. Army Research Laboratory \\ Glenn Research Center \\ Cleveland, Ohio 44135 \\ Email: Donald.L.Simon@grc.nasa.gov
}

\begin{abstract}
In this paper, a bank of Kalman filters is applied to aircraft gas turbine engine sensor and actuator fault detection and isolation (FDI) in conjunction with the detection of component faults. This approach uses multiple Kalman filters, each of which is designed for detecting a specific sensor or actuator fault. In the event that a fault does occur, all filters except the one using the correct hypothesis will produce large estimation errors, thereby isolating the specific fault. In the meantime, a set of parameters that indicate engine component performance is estimated for the detection of abrupt degradation. The proposed FDI approach is applied to a nonlinear engine simulation at nominal and aged conditions, and the evaluation results for various engine faults at cruise operating conditions are given. The ability of the proposed approach to reliably detect and isolate sensor and actuator faults is demonstrated.
\end{abstract}

$\begin{array}{ll}\text { NOMENCLATURE } \\ \text { A16 } & \text { Variable bypass duct area } \\ \text { A8 } & \text { Nozzle area } \\ \text { BST } & \text { Booster } \\ \text { CLM } & \text { Component Level Model } \\ \text { FAN } & \text { Fan } \\ \text { FDI } & \text { Fault detection and isolation } \\ \text { FOD } & \text { Foreign object damage } \\ \text { HPC } & \text { High-pressure compressor } \\ \text { HPT } & \text { High-pressure turbine } \\ \text { LPT } & \text { Low-pressure turbine } \\ \text { P27 } & \text { HPC inlet pressure } \\ \text { PS15 } & \text { Bypass duct static pressure } \\ \text { PS3 } & \text { Combustor inlet static pressure } \\ \text { PS56 } & \text { LPT exit static pressure } \\ \text { T27D } & \text { Booster inlet temperature } \\ \text { T56 } & \text { LPT exit temperature }\end{array}$

$\begin{array}{ll}\text { TMPC } & \text { Burner exit heat soak } \\ \text { WF36 } & \text { Fuel flow } \\ \text { XN2 } & \text { Low-pressure spool speed, measured } \\ \text { XN25 } & \text { High-pressure spool speed, measured } \\ \text { XNH } & \text { High-pressure spool speed, state variable } \\ \text { XNL } & \text { Low-pressure spool speed, state variable }\end{array}$

\section{INTRODUCTION}

Fault detection and isolation (FDI) logic plays a critical role in enhancing the safety and reliability and reducing the operating cost of aircraft propulsion systems. However, achieving the FDI task with high reliability is a challenging problem. Faults may occur in various degrees of severity at various locations; therefore numerous fault scenarios are possible. Moreover, the engine's complex structure and harsh operating environment make interpretation of the available information difficult. To deal with such problems, the introduction of analytical redundancy has become common and is considered more cost-effective than hardware redundancy. With the increase of digital computational power, more sophisticated approaches such as the utilization of an on-board engine model have become possible.

When a fault occurs, the first step is to detect it as soon as possible so that the scenario of a minor fault escalating to a more serious failure can be avoided. The approach commonly used for model-based fault detection is composed of two steps: 1) generate residual signals from the sensor measurements and their estimated values, and then 2) compare the residuals with thresholds to make fault detection decisions [1]. Sensor noise and modeling uncertainty are key factors that affect detection performance. A fault signature contained in the measurements is often corrupted by sensor noise, and un-modeled engine dynamics may generate a fault-like signature. These factors lead to missed detections and false alarms. To reduce the effects of noise, the sensor measurements can be averaged over a given length of time. Although this approach may remove spike-like fault signatures, 
it can retain fault information which spans a period of time. To deal with modeling uncertainty, robust detection approaches have been investigated by some researchers [2,3]. In the robust design approach, modeling uncertainty is accounted for in the residual generation process. Therefore, fault detection logic can be sensitive to faults while being robust to modeling uncertainty.

Once a fault is successfully detected, the next step is to isolate the particular fault from other potential faults. A single fault isolation technique for aircraft engine performance diagnostics was investigated by Volponi et al. [4]. Assuming that a fault has already been detected, this approach processed Kalman filter equations iteratively for each of the root causes under consideration and subsequently ranked fault candidates in order of likelihood based on the estimation error norms. The application of a bank of estimators for fault detection and isolation was conducted by Merrill et al. [5], Duyar et al. [6], and Menke et al. [7]. This approach uses multiple estimators, each of which is designed for detecting a specific fault. Since each estimator is designed based on a specific hypothesis (such as the failure of a single sensor or actuator), all the estimators except the one using the correct hypothesis will produce large estimation errors when a fault occurs. By monitoring the residual of each estimator, the specific fault that has occurred can be detected and isolated.

The use of a bank of Kalman filters for addressing aircraft engine sensor failures was investigated by NASA's Advanced Detection, Isolation, and Accommodation (ADIA) Program during the 1980's [5]. This program successfully demonstrated improved control loop tolerance to sensor failures (bias and drift) using the aforementioned analytical technique. It did not, however, address robustness issues in the presence of engine degradation or other faults. Over their lifetime of operation, engine components will undergo some amount of degradation. This degradation may be gradual or abrupt as in the case of foreign object damage. If abrupt component degradation has occurred, a sensor FDI system may generate a false alarm. Similarly, an actuator failure may cause a false alarm or missed detection if not considered. In the new framework, actuator and component faults are accounted for to expand the FDI capability.

The proposed FDI approach is applied to a nonlinear engine simulation and evaluated for various engine faults at cruise operating conditions. In order to mimic the real engine environment, the nonlinear simulation is executed not only at the nominal, or healthy, condition but also at an aged condition. Although the effectiveness of the FDI system is impacted by aging engine effects, a simple approach to recover the performance is discussed and evaluated.

\section{DEVELOPMENT OF FAULT DETECTION AND ISOLATION LOGIC}

A depiction of the FDI logic integrated with the propulsion system is shown in Fig. 1. The FDI logic uses two sets of input signals: sensor measurements and control commands. Sensor measurements are corrupted by noise and may be faulty due to sensor failure. Actuators may also experience mechanical and/or electrical failures. As shown in Fig. 1, the FDI logic uses control commands $\left(u_{c m d}\right)$. Alternatively, the true actuator positions $\left(u_{\text {true }}\right)$ may be directly measured, and the sensed values may be used by the FDI logic. However, using sensed actuator positions would add complexity to the FDI problem, since an actuator fault can happen not only to an actuator itself but also to an actuator position feedback sensor. Therefore, an actuator fault is simply defined as an inconsistency between true actuator position and control command. The sensor and actuator failures dealt with in this paper are so-called "soft" failures. Soft failures are defined as inconsistencies between true and measured

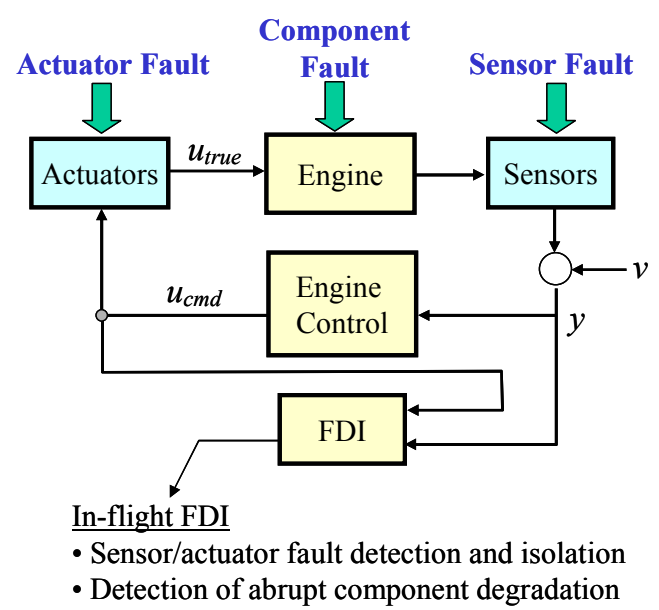

\section{Figure 1. Propulsion System with Fault Detection and Isolation Logic}

sensor values (or true and commanded actuator values) that are relatively small in magnitude and thus difficult to detect by a simple range-checking approach, whereas "hard" failures are larger in magnitude and thus more readily detectable. Soft failures can take different forms such as a fixed scalar, a fixed bias, a drift, or intermittent spikes. Among these failures, fixed bias is investigated in this study, although the proposed approach can be applied to timevarying soft failures as well.

In the development of the FDI logic, it is assumed that only one of the sensors or actuators will fail at a time. Multiple sequential and multiple simultaneous failures are not addressed in this paper. The likelihood of multiple simultaneous failures is considered to be very low. To handle multiple sequential failures, a hierarchical fault isolation structure, as demonstrated by Menke et al. [7], must be added to the proposed FDI logic. In the following sections, the approach for sensor and actuator FDI in conjunction with component fault detection is discussed.

\section{Component Performance Analysis}

Engine component performance is represented by a set of so-called health parameters. The health parameters deviate from initial healthy baseline values as the components degrade; therefore they are an indicator of the engine internal condition. A linear engine model under consideration is represented by the following state-space equations:

$$
\begin{aligned}
& \dot{x}=A x+L h+B u_{c m d} \\
& y=C x+M h+D u_{c m d}+v
\end{aligned}
$$

where the vectors $x, h, u_{c m d}$ represent state variables, health parameters, and control variables, respectively. The sensor measurement vector, $y$, is corrupted by the sensor noise vector, $v$. The matrices $A, B, C, D, L$, and $M$ have appropriate dimensions. The influence of health parameters on an engine is similar to that of the control variables, however, the health parameters are not measurable and are thus treated as a part of the augmented state to be estimated. 
In the Kalman filter problem setup, the engine state vector is augmented with health parameters as follows [8]:

$$
\begin{aligned}
& \dot{\dot{x}}=\widetilde{A} \widetilde{x}+\widetilde{B} u_{c m d}+w \\
& y=\widetilde{C} \widetilde{x}+D u_{c m d}+v
\end{aligned}
$$

where

$$
\widetilde{x}=\left[\begin{array}{l}
x \\
h
\end{array}\right], \widetilde{A}=\left[\begin{array}{ll}
A & L \\
0 & 0
\end{array}\right], \widetilde{B}=\left[\begin{array}{l}
B \\
0
\end{array}\right], \widetilde{C}=\left[\begin{array}{ll}
C & M
\end{array}\right]
$$

and $w$ and $v$ are the process and sensor noise, respectively. They are uncorrelated, white noise with the following covariance matrices:

$$
\begin{aligned}
& E\left[w(t+\tau) w^{T}(t)\right]=Q \delta(\tau) \\
& E\left[v(t+\tau) v^{T}(t)\right]=R \delta(\tau)
\end{aligned}
$$

The Kalman filter has the following structure:

$$
\begin{aligned}
& \dot{\vec{x}}_{e}=\widetilde{A} \widetilde{x}_{e}+\widetilde{B} u_{c m d}+K\left(y-y_{e}\right) \\
& y_{e}=\widetilde{C} \widetilde{x}_{e}+D u_{c m d}
\end{aligned}
$$

where $\tilde{x}_{e}$ and $y_{e}$ are the estimates of augmented state vector and sensor measurements, respectively, and $K$ is a Kalman gain matrix. In general, the matrix $R$ is derived from available sensor noise characteristic data while the matrix $Q$ is tuned for obtaining a desired Kalman gain. In order for the Kalman filter to converge, the matrix pair $(\widetilde{A}, \widetilde{C})$ must be observable. Moreover, the current problem setup requires the number of health parameters in the augmented state vector to be less than or equal to the number of sensor measurements [9]. The above state-augmented approach is used for designing a bank of Kalman filters.

\section{Sensor Fault Detection}

The bank of Kalman filters for sensor fault detection and isolation, shown in Fig. 2, contains $m$ Kalman filters where $m$ is the number of sensors being monitored. Each filter estimates the augmented state vector discussed in the previous section using $(m-1)$ sensors. The sensor which is not used by a particular filter is the one being monitored by that filter for fault detection. For instance, the $i^{\text {th }}$ filter uses the sensor subset $y^{i}$ that excludes the $i^{\text {th }}$ sensor, where $i$ is an integer from 1 to $m$. In the event that sensor $\# i$ is faulty, all filters will use a corrupted measurement, except for filter $\# i$. Consequently, filter $\# i$ is able to estimate the augmented state vector from fault-free sensor measurements, whereas the estimates of the remaining filters are distorted by the fault in sensor $\# i$.

After the estimation of augmented state variables, the sensor measurement estimates are constructed as described in Eq. (4). In order to evaluate the accuracy of the state estimation, the following residual vector is generated for each filter:

$$
e^{i}=y_{e}^{i}-y^{i}
$$

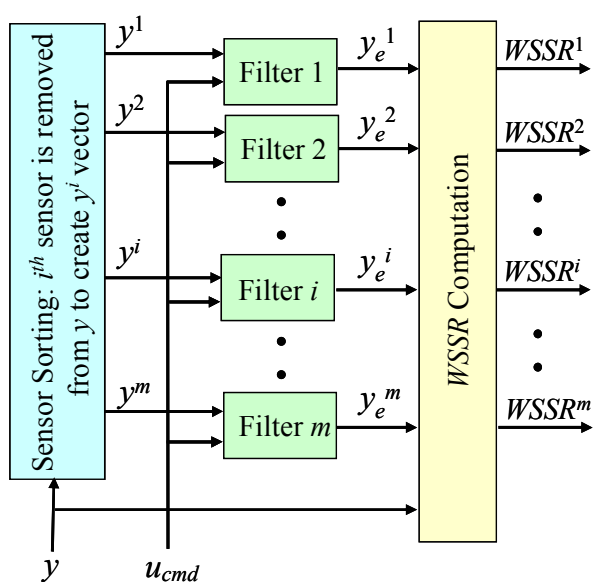

Figure 2. Structure of Bank of Kalman Filters

From this residual, a weighted sum of squared residual (WSSR) is computed:

$$
W_{S S R}^{i}=W_{r}^{i}\left(e^{i}\right)^{T}\left(\Sigma^{i}\right)^{-1} e^{i}
$$

where

$$
\Sigma^{i}=\operatorname{diag}\left[\sigma^{i}\right]^{2}
$$

The vector $\sigma^{i}$ represents the standard deviations of the $i^{\text {th }}$ sensorsubset, and it normalizes the residual vector. The additional weight $W_{r}$ is a scalar, and it is selected so that the value of the WSSR signal will be less than a given threshold under the normal condition where all sensors are fault free. The scalar $W_{r}$ is a tuning parameter that influences the FDI performance. If the weight $W_{r}$ is too small, the increase in WSSR due to a faulty sensor will not be observed, causing missed detections. On the other hand, if this scalar is too large, the WSSR signal will be too sensitive to sensor noise and modeling uncertainty and may generate false alarms. The fault indicator signal (i.e., WSSR) in Eq. (6) will be compared against the detection threshold in order to detect a sensor fault.

\section{Actuator Fault Detection}

Actuator FDI is more challenging than sensor FDI in model-based estimation approaches. In the general Kalman filter approach, it is assumed that the actuators are properly configured to the positions that a control system demands, thus any engine responses to actuator perturbations are cancelled out in the estimation loop. However, if a large discrepancy between commanded and true actuator positions does exist due to an actuator fault, it can result in significant state estimation errors. In this paper, an actuator fault is modeled as a bias, which results in an inconsistency between an actuator command used as a Kalman filter input and a true actuator position under which the engine is operating.

To account for a potential bias, the following linear engine model is used in the actuator FDI design approach: 


$$
\begin{aligned}
& \dot{x}=A x+L h+B\left(u_{c m d}+b\right) \\
& y=C x+M h+D\left(u_{c m d}+b\right)+v
\end{aligned}
$$

Equation (7) shows the actuator bias vector $b$ added to the actuator command inputs.

A bank of Kalman filters is also applied for the actuator FDI though its structure will be different from that of the sensor FDI. Unlike the sensor FDI approach where each filter excludes one sensor from the sensor suite, each filter in the actuator FDI will use all $m$ sensors and estimate an augmented state vector, which includes an actuator bias. Similar to the sensor FDI approach, the engine state variables in Eq. (1) are augmented with the health parameters and, in addition, one actuator bias. For the bias estimation of the $k^{\text {th }}$ actuator, the following model equation is used:

$$
\begin{aligned}
& \dot{\tilde{x}}^{k}=\widetilde{A}^{k} \tilde{x}^{k}+\widetilde{B} u_{c m d}+w \\
& y^{k}=\widetilde{C}^{k} \widetilde{x}^{k}+D u_{c m d}+v
\end{aligned}
$$

where

$$
\widetilde{x}^{k}=\left[\begin{array}{c}
x \\
h \\
b_{k}
\end{array}\right], \widetilde{A}^{k}=\left[\begin{array}{ccc}
A & L & B_{k} \\
0 & 0 & 0 \\
0 & 0 & 0
\end{array}\right], \widetilde{B}=\left[\begin{array}{c}
B \\
0 \\
0
\end{array}\right], \widetilde{C}^{k}=\left[\begin{array}{lll}
C & M & D_{k}
\end{array}\right]
$$

and $k$ is an integer from 1 to $p$, where $p$ is the number of actuators. The scalar $b_{k}$ is a bias in the $k^{\text {th }}$ actuator, and the vectors $B_{k}$ and $D_{k}$ are the $k^{\text {th }}$ columns of $B$ and $D$ matrices, respectively. Based on the above state-space structure, a Kalman filter for each actuator is designed using Eqs. (3) and (4).

After the estimation of the augmented state variables and sensor measurements, a fault indicator signal is generated for each filter similar to the sensor FDI approach. The residual signal of the $(m+k)^{\text {th }}$ filter is given as:

$$
e^{m+k}=y_{e}^{k}-y
$$

where the vector $y_{e}^{k}$ is the sensor estimates generated by the $(m+k)^{\text {th }}$ filter. From this signal, the following weighted sum of squared residual (WSSR) is generated:

$$
W_{S S R}^{m+k}=V_{r}^{k}\left(e^{m+k}\right)^{T}(\Sigma)^{-1} e^{m+k}
$$

where

$$
\Sigma=\operatorname{diag}[\sigma]^{2}
$$

The vector $\sigma$ is the noise standard deviation, and the scalar $V_{r}$ is a weighting factor for the FDI performance trade off. The fault indicator signal (WSSR) in Eq. (10) will be compared against a given detection threshold in order to detect an actuator fault. When an actuator is biased, all filters use corrupted information, however, the one filter with the correct hypothesis is able to accommodate it. Therefore, this particular filter will maintain a low residual value and consequently can be isolated from the rest of the filters.

\section{Integration of Bank of Kalman Filters with Fault Isolation Logic}

The overall architecture of the FDI system is shown in Fig. 3. The functionality of the bank of Kalman filters with an augmented state vector is summarized as follows.

1) When there is no sensor or actuator fault, with or without component faults, all Kalman filters should retain low fault indicator signals, indicating there is no sensor/actuator fault, and should generate accurate health parameter estimates.

2) When one of the sensors or actuators failed, with or without component faults, only the one filter with the correct hypothesis should generate a low fault indicator signal and accurate health parameter estimates.

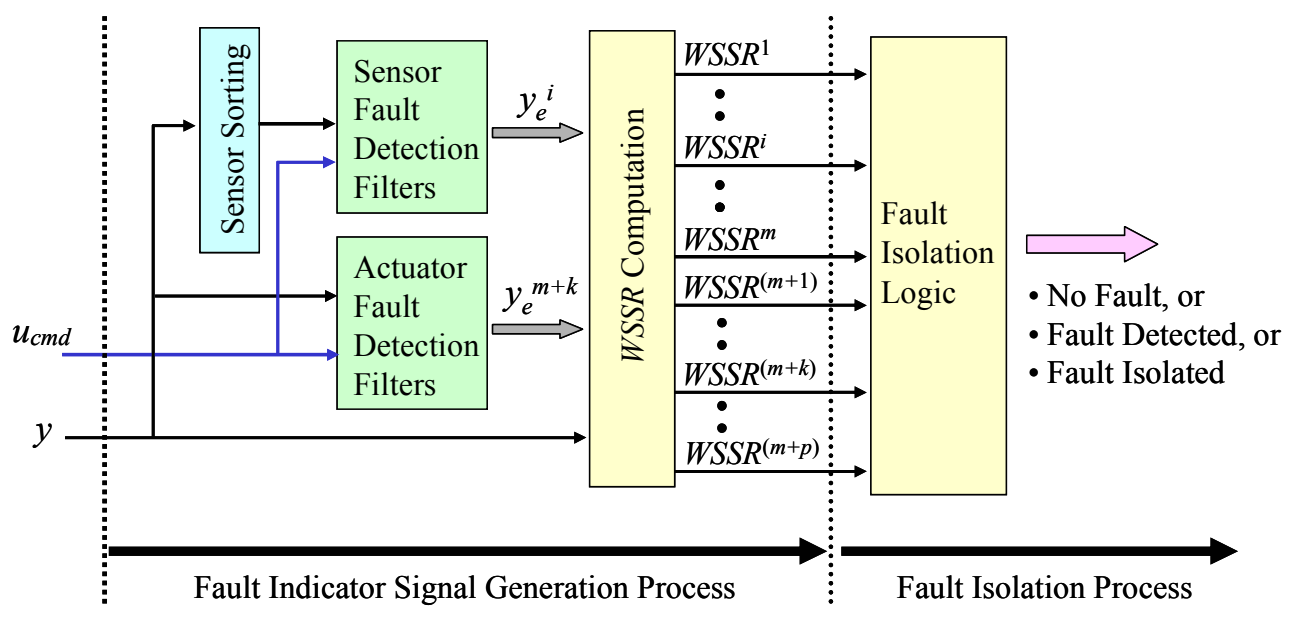

Figure 3. FDI System Architecture 
The fault indicator signals generated by the above approach must be further processed in order to identify a fault. The FDI process can be completed by integrating the bank of Kalman filters with fault isolation logic as shown in Fig. 3. In general, fault isolation logic is constructed from detection thresholds and decision rules. The decision rules check for fault indicator signal violation of the pre-established detection thresholds. If the necessary rules for the existence of a fault are satisfied, then the fault isolation logic declares a fault. Fault isolation is achieved if a fault is declared for all the fault indicator signals except for the one corresponding to a correct fault hypothesis. The development of fault isolation logic is application-dependent. An example will be given in the following section where the FDI design methodology is applied to an aircraft engine model.

\section{APPLICATION OF FDI METHODOLOGY TO AN AIRCRAFT ENGINE}

In this section, the FDI design methodology is applied to an aircraft engine model. A description of the engine model will be given, followed by a description of the fault isolation logic development.

\section{Engine Model}

The engine model used in the current research is the nonlinear simulation of an advanced military twin-spool turbofan engine [10]. This simulation is constructed as a Component Level Model (CLM), which assembles the major components of an aircraft engine. Engine performance deterioration is modeled by adjustments to efficiency and/or flow coefficient scalars of the following five components: Fan (FAN), Booster (BST), High-Pressure Compressor (HPC), HighPressure Turbine (HPT), and Low-Pressure Turbine (LPT). These scalars representing the component performance deterioration are referred to as health parameters. The actuator dynamics are much faster than the engine dynamics. The engine state variables, health parameters, actuation variables, and sensor measurements used in the current research are shown in Table 1.

Table 1. State, Health, Actuator, and Sensor Variables

\begin{tabular}{|l||l|}
\hline State Variables & XNL, XNH, TMPC \\
\hline Health & FAN efficiency, FAN flow capacity \\
Parameters & BST efficiency, BST flow capacity \\
& HPC efficiency, HPC flow capacity \\
& HPT efficiency, HPT flow capacity \\
& LPT efficiency, LPT flow capacity \\
\hline Actuators & WF36, A8, A16 \\
\hline Sensors & XN2, XN25, T27D, T56, PS15, P27, PS3, \\
& PS56 \\
\hline
\end{tabular}

In this paper, the standard deviations of the sensor noise shown in Table 2 are used. These numbers are rough estimates derived from $\mathrm{Lu}$ et al. [11]. Information regarding sensor accuracy can be also found in Pinelli et al. [12].

An assumption is made in this application problem. It is assumed that the first four health parameters (FAN and BST efficiency and flow capacity scalars) in Table 1 are sufficient to represent component faults of interest during a flight. The health parameters represent engine internal condition. These parameters deviate from initial healthy baseline values over time due to gradual degradation (aging phenomenon) and possibly abrupt degradation (fault). The focus of the current research is the detection of faults rather than the trending of
Table 2. Sensor Noise Standard Deviation in $\%$ of the Nominal Engine Trim Values

\begin{tabular}{|c|c|}
\hline Sensor & $\sigma$ \\
\hline \hline XN2 & 0.25 \\
\hline XN25 & 0.25 \\
\hline T27D & 0.50 \\
\hline T56 & 0.50 \\
\hline PS15 & 0.50 \\
\hline P27 & 0.50 \\
\hline PS3 & 0.50 \\
\hline PS56 & 0.50 \\
\hline
\end{tabular}

component performance deterioration due to aging. The four health parameters are used to represent an abrupt, moderate degradation due to foreign object damage (FOD), as done by Kerr et al. [13]. The detection of such component faults is achieved by accurately estimating those selected health parameters. Therefore, they are included in the augmented state vector and estimated as described by Eqs. (2) through (4). The selection of the four health parameters was based upon their correlation to FOD events and the relative likelihood of an engine experiencing FOD versus other possible abrupt component degradations during a flight. If alternative faults are known to be more probable, the FDI system can be re-designed using those health parameters which correlate to the faults of interest. The design constraint is that the selected health parameters must be observable through the given sensor suite.

\section{Development of Fault Isolation Logic}

In order to isolate a fault using the bank of Kalman filters developed in the previous sections, fault isolation logic must be developed. This decision-making logic is discussed in this section in the context of a simulated example. Consider an example in which the fault indicator signal generation process in Fig. 3 is applied to the nonlinear engine simulation for a scenario where all the sensors and actuators remain fault free. Figure 4 shows the fault indicator signals (WSSR) for the selected FDI filters; these signals have been filtered through a lowpass filter with a cutoff frequency of $1.0 \mathrm{rad} / \mathrm{sec}$. The noise in the sensor measurements is quite significant and causes large variations in the health parameter estimates and the fault indicator signals.
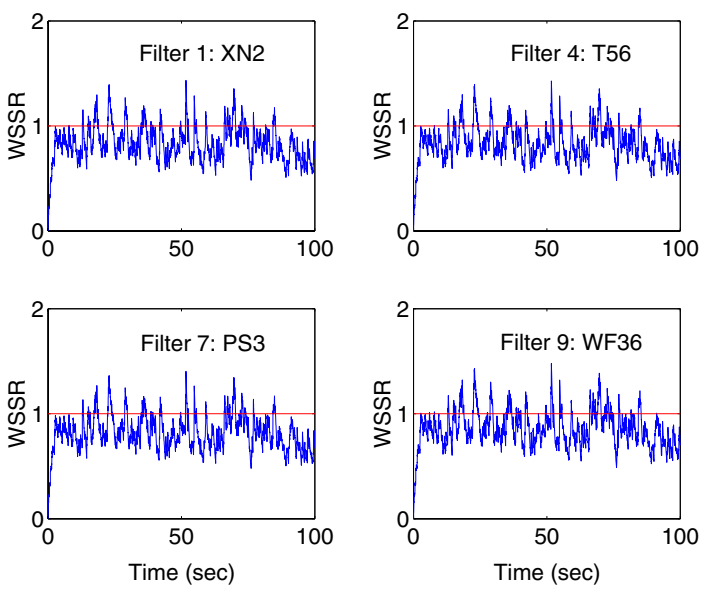

Figure 4. Fault Indicator Signals of Select FDI Filters 
Two factors that are of main concern in developing the fault isolation logic are false alarms and missed detections. Reducing one of these factors often causes an increase in the other. To illustrate how the isolation logic affects false alarms and missed detections, assume that, in the current case, a fault is declared for an FDI filter when the corresponding fault indicator signal exceeds a given detection threshold. If the detection threshold is set at the value of one, all of the fault indicator signals in Fig. 4 exceed the detection threshold; therefore multiple false alarms would have occurred. To avoid such false alarms, two options are possible: 1) increase the detection threshold value, or 2) smooth the fault indicator signals by modifying the bandwidth of the low-pass filter. Both options, however, may cause missed detections. A fault may result in a shift in the mean value of some fault indicator signals without any spike-like responses. In such a case, a failure scenario will go undetected until the magnitude of the fault becomes severe enough to reach the higher threshold. Also, reducing the bandwidth of the low-pass filter will eliminate any spike-like fault signatures in the fault indicator signals, making such failures more difficult to detect.

In the current study, a modified approach for fault isolation is developed in order to reduce false alarms and missed detections as much as possible. First of all, the fault indicator signals of all 11 Kalman filters are averaged over non-overlapping, ten-second intervals. For sensor FDI filters, two thresholds are used: the first threshold is set at the value of one, and the second is set at the value of two. A fault is declared if the ten-second averaged fault indicator signal exceeds the first threshold three consecutive times, or if the non-averaged fault signal exceeds the second threshold. The first rule (using the averaged signal) addresses a mean value shift of the fault indicator signal that is sustained. This rule results in a minimum fault identification time of 30 seconds. The second rule (using the nonaveraged signal) obviously takes into account spike-like fault signatures. The second threshold is set high enough so that sensor noise or modeling uncertainty will not cause the fault indicator signal to exceed it.

For actuator FDI filters, only one threshold, set at the value of one, is used. A fault is declared if the ten-second averaged fault indicator signal exceeds the threshold four consecutive times. The reason for applying a different rule for actuator failures is as follows. For actuator FDI, the response of the "correct" Kalman filter is influenced by an actuator bias, whereas a sensor bias does not influence the response of the "correct" filter for sensor FDI. When an actuator is biased, the actuator position estimated by the "correct" Kalman filter initially follows the control command, indicating that there is no bias. After going through this initial error phase, the estimated position starts converging to the true actuator position. This initial estimation error can be huge depending on the bias magnitude. Therefore, spikelike signatures, which could be generated by both "correct" and "wrong" filters, cannot be used as an actuator fault indicator. Moreover, the initial estimation error transient of the "correct" Kalman filter may result in high residuals which persist for longer periods than in the sensor FDI case. To account for this fact, the detection threshold must be violated four consecutive times before declaring a fault, instead of three times as for the sensor FDI.

Fault isolation is successfully achieved when the fault isolation logic detects a fault in all filters except for the one "correct" filter. If a "wrong" filter is isolated, it is considered a false alarm. If the isolation logic detects a fault in at least one filter, but multiple filters indicate no-fault, it means that a fault was detected but not isolated. FDI performance depends on the decision rules and the values of the detection thresholds. They are adjusted by the designer in order to meet the desired system performance requirements.

\section{PERFORMANCE EVALUATION OF THE FDI SYSTEM}

The performance of the FDI system is evaluated in this section by applying it to the nonlinear engine simulation trimmed at a cruise operating point. The FDI performance is evaluated based on the minimum sensor/actuator bias magnitude which can be isolated, and the accuracy of health parameter estimates. Multiple scenarios are considered to ensure that the FDI system does not identify any component faults as a sensor or actuator fault. To capture a range of expected component faults, the eight scenarios, shown in Table 3 with health parameter and control command perturbation magnitude and

Table 3. Engine Operation Scenarios for Evaluation of the FDI System

\begin{tabular}{|c|c|c|c|c|c|c|c|}
\hline \multirow[b]{2}{*}{$\begin{array}{c}\text { Scenario } \\
\#\end{array}$} & \multicolumn{7}{|c|}{ Perturbation Description (magnitude and step time) } \\
\hline & $\begin{array}{c}\text { FAN } \\
\text { efficiency }\end{array}$ & $\begin{array}{l}\text { FAN } \\
\text { flow }\end{array}$ & $\begin{array}{c}\text { BST } \\
\text { efficiency }\end{array}$ & $\begin{array}{l}\text { BST } \\
\text { flow }\end{array}$ & WF36 & A8 & A16 \\
\hline 1 & 0 & 0 & 0 & 0 & 0 & 0 & 0 \\
\hline 2 & 0 & 0 & 0 & 0 & $\begin{array}{c}2 \% \\
\text { at } 5 \mathrm{sec}\end{array}$ & $\begin{array}{c}-1 \% \\
\text { at } 8 \mathrm{sec}\end{array}$ & $\begin{array}{c}-3 \% \\
\text { at } 7 \mathrm{sec}\end{array}$ \\
\hline 3 & $\begin{array}{c}-1 \% \\
\text { at } 5 \mathrm{sec}\end{array}$ & $\begin{array}{c}-1 \% \\
\text { at } 6 \mathrm{sec}\end{array}$ & $\begin{array}{c}-1 \% \\
\text { at } 10 \mathrm{sec}\end{array}$ & $\begin{array}{c}-1 \% \\
\text { at } 12 \mathrm{sec}\end{array}$ & 0 & 0 & 0 \\
\hline 4 & $\begin{array}{c}-1 \% \\
\text { at } 5 \mathrm{sec} \\
\end{array}$ & $\begin{array}{c}-1 \% \\
\text { at } 6 \mathrm{sec} \\
\end{array}$ & $\begin{array}{c}-1 \% \\
\text { at } 10 \mathrm{sec} \\
\end{array}$ & $\begin{array}{c}-1 \% \\
\text { at } 12 \mathrm{sec} \\
\end{array}$ & $\begin{array}{c}2 \% \\
\text { at } 20 \mathrm{sec} \\
\end{array}$ & $\begin{array}{c}-1 \% \\
\text { at } 23 \mathrm{sec} \\
\end{array}$ & $\begin{array}{c}-3 \% \\
\text { at } 22 \mathrm{sec} \\
\end{array}$ \\
\hline 5 & $\begin{array}{c}-2 \% \\
\text { at } 5 \mathrm{sec}\end{array}$ & $\begin{array}{c}-2 \% \\
\text { at } 6 \mathrm{sec} \\
\end{array}$ & $\begin{array}{c}-2 \% \\
\text { at } 10 \mathrm{sec}\end{array}$ & $\begin{array}{c}-2 \% \\
\text { at } 12 \mathrm{sec}\end{array}$ & 0 & 0 & 0 \\
\hline 6 & $\begin{array}{c}-2 \% \\
\text { at } 5 \mathrm{sec} \\
\end{array}$ & $\begin{array}{c}-2 \% \\
\text { at } 6 \mathrm{sec}\end{array}$ & $\begin{array}{c}-2 \% \\
\text { at } 10 \mathrm{sec}\end{array}$ & $\begin{array}{c}-2 \% \\
\text { at } 12 \mathrm{sec}\end{array}$ & $\begin{array}{c}2 \% \\
\text { at } 20 \mathrm{sec} \\
\end{array}$ & $\begin{array}{c}-1 \% \\
\text { at } 23 \mathrm{sec} \\
\end{array}$ & $\begin{array}{c}-3 \% \\
\text { at } 22 \mathrm{sec}\end{array}$ \\
\hline 7 & $\begin{array}{c}-3 \% \\
\text { at } 5 \mathrm{sec}\end{array}$ & $\begin{array}{c}-3 \% \\
\text { at } 6 \mathrm{sec}\end{array}$ & $\begin{array}{c}-3 \% \\
\text { at } 10 \mathrm{sec}\end{array}$ & $\begin{array}{c}-3 \% \\
\text { at } 12 \mathrm{sec}\end{array}$ & 0 & 0 & 0 \\
\hline 8 & $\begin{array}{c}-3 \% \\
\text { at } 5 \mathrm{sec}\end{array}$ & $\begin{array}{c}-3 \% \\
\text { at } 6 \mathrm{sec}\end{array}$ & $\begin{array}{c}-3 \% \\
\text { at } 10 \mathrm{sec}\end{array}$ & $\begin{array}{c}-3 \% \\
\text { at } 12 \mathrm{sec}\end{array}$ & $\begin{array}{c}2 \% \\
\text { at } 20 \mathrm{sec}\end{array}$ & $\begin{array}{c}-1 \% \\
\text { at } 23 \mathrm{sec}\end{array}$ & $\begin{array}{c}-3 \% \\
\text { at } 22 \mathrm{sec}\end{array}$ \\
\hline
\end{tabular}


injection time information, are investigated. In the simulation, these perturbations are injected as step changes at the specified time. The perturbations in the four health parameters represent abrupt component degradation due to a FOD event. Since field data indicating actual component degradation profiles due to FOD was not available, the magnitudes and injection times were selected arbitrarily. Likewise, control command perturbations were selected arbitrarily to represent operation around the fixed operating point. As shown in Table 3, multiple health parameters are perturbed in order to introduce the nonlinear effects on the engine simulation outputs. The control command perturbations disturb the engine operating point; however, they must not cause a false alarm.

\section{Robustness Issues of the FDI System Toward Engine Uncertainty Due to Aging}

In the real engine environment, a mismatch in the health condition between an operational (aging) engine and the "nominal" engine model used by the FDI system almost always exists. It is well known that the physical engine components deteriorate gradually due to wear and tear on blades and casing as an engine operates over time [14]. In this paper, such gradual component deterioration is referred to as "baseline degradation" and is represented by deviations in all 10 health parameters. Two baseline conditions used for FDI performance evaluation are shown in Table 4. The FDI system is applied to the nonlinear simulation at these two baseline conditions for each of the eight scenarios in Table 3. The current FDI design does not account for the changes in the baseline condition, i.e., the bank of Kalman filters is designed based on the healthy engine baseline. Therefore, if the FDI system is applied to the nonlinear engine simulation at baseline condition $\# 2$, the baseline mismatch will impact the FDI performance. It should be noted that the abrupt health parameter perturbations in Table 3 are deviations from the baseline conditions in Table 4. Therefore, a 3\% reduction in FAN flow capacity (Scenarios 7 and 8 ) for engine baseline \#2 (Table 4) means 5.2\% degradation in total.

Table 4. Baseline Degradations in \% from the Nominal Baseline Condition

\begin{tabular}{|l|c|c|}
\hline & $\begin{array}{c}\text { Baseline 1: } \\
\text { Nominal (Healthy) }\end{array}$ & $\begin{array}{c}\text { Baseline 2: } \\
\text { Degraded }\end{array}$ \\
\hline FAN efficiency & 0 & -1.80 \\
\hline FAN flow & 0 & -2.20 \\
\hline BST efficiency & 0 & -2.00 \\
\hline BST flow & 0 & -2.20 \\
\hline HPC efficiency & 0 & -1.50 \\
\hline HPC flow & 0 & -1.20 \\
\hline HPT efficiency & 0 & -2.00 \\
\hline HPT flow & 0 & 1.50 \\
\hline LPT efficiency & 0 & -1.20 \\
\hline LPT flow & 0 & 2.00 \\
\hline
\end{tabular}

The effects of baseline mismatch on the FDI performance are shown in Table 5 where the FDI system was applied to the nonlinear simulation at the two baseline conditions. The simulation was run without any health parameter or control perturbations (Scenario 1) and without any sensor or actuator faults.

Table 5 shows the estimation performance of the FDI filter \#1 which is designed to monitor the XN2 sensor. All estimation values were averaged over 100 seconds. Note that this FDI filter constructs the sensor bias estimate from the estimated state variables. As expected, the deviations in all 10 health parameters (baseline degradation) for condition \#2 are incorrectly attributed, or "smeared," to the four health parameters being estimated, resulting in unacceptable health estimation. A similar result was observed in real engine testing conducted by Luppold et al. [15]. Moreover, the overall sensor/actuator FDI performance appeared to vary with the baseline condition: none of the FDI filters declared a fault for the baseline condition $\# 1$, whereas all 11 FDI filters declared a fault for the baseline condition \#2. This example demonstrates the sensitivity of the FDI system, which is designed based on a healthy engine, to the baseline degradation of aging engines.

Table 5. Estimation Performance of the FDI Filter \#1, XN2 (Simulation Scenario 1 without Sensor or Actuator Fault)

\begin{tabular}{|c|c|c|c|c|c|}
\cline { 2 - 6 } \multicolumn{1}{c|}{} & \multicolumn{5}{c|}{ Average Estimation of Filter \#1 (XN2) } \\
\hline $\begin{array}{c}\text { Nonlinear } \\
\text { Baseline } \\
\text { Condition }\end{array}$ & $\begin{array}{c}\text { Sensor } \\
\text { Bias } \\
(\% \text { of trim })\end{array}$ & $\begin{array}{c}\text { FAN } \\
\text { Efficiency } \\
(\%)\end{array}$ & $\begin{array}{c}\text { FAN } \\
\text { Flow } \\
(\%)\end{array}$ & $\begin{array}{c}\text { BST } \\
\text { Efficiency } \\
(\%)\end{array}$ & $\begin{array}{c}\text { BST } \\
\text { Flow } \\
(\%)\end{array}$ \\
\hline 1 & -0.03 & -0.05 & -0.11 & 0.09 & 0.05 \\
\hline 2 & -3.95 & -11.45 & -13.98 & 1.37 & 6.13 \\
\hline
\end{tabular}

The loss of FDI performance due to aging effects can be partially recovered by modifying any of the following three parts of the FDI system shown in Fig. 7: 1) Trim Value Data, 2) Bank of Kalman Filters, and 3) Fault Isolation Logic.

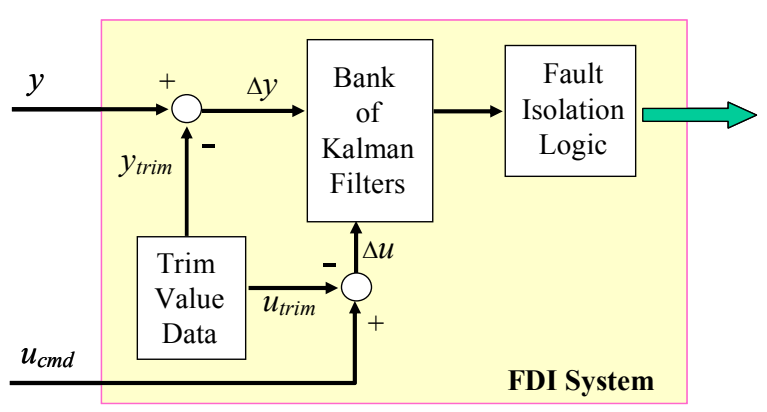

Figure 7. Structure of the FDI System

The trim value data contains sensor and actuator steady-state values at a trim condition where the bank of Kalman filters is designed. As the baseline degradation worsens, the difference in the steady-state values at the trim point between the degraded and healthy engines increases, causing a loss of FDI performance. If the trim value data is updated to account for baseline degradation, the initial steady-state estimation errors can be eliminated. Since the baseline degradation progresses gradually, such a trim value update can be performed after a number of flights through off-line trend monitoring as done by Kobayashi et al. [16] and Volponi [17]. In this approach, a mismatch between the dynamics of the operational engine and the nominal model used by the FDI system may still exist. A more involved option for reducing the estimation error is to update the bank of Kalman filters based on the baseline degradation. After updating the trim 
value data, a linear model can be generated at the corresponding trim condition. By designing a bank of Kalman filters based on this linear model, both the initial steady-state condition and the dynamics of the FDI system will match with those of the operational engine. The ease with which such linear model generation can be achieved is key for making this approach practical. Another option for regaining the lost FDI performance is to modify the fault isolation logic. The difference in the initial steady-state values between the operational engine and the nominal trim value data causes an increase in the steady-state values of the fault indicator signals. By simply setting the threshold at a higher value, a false alarm can be avoided. However, this approach results in conservative performance when the operational engine is healthy. Among the three options discussed above, the first option (updating the trim value data) is the simplest approach. This option will be evaluated in the following section.

\section{Evaluation Results}

In this section, the performance of the FDI system is evaluated by applying it to the nonlinear simulation for the eight scenarios in Table 3. For each scenario, the nonlinear simulation is executed for 100 seconds at the two baseline conditions shown in Table 4. When the FDI system is applied to the nonlinear simulation at baseline condition $\# 2$, the trim value data is updated, assuming an updating technique is available, so that the initial steady-state mismatch is eliminated.

A sensor or actuator bias is injected as a step change when the simulation time reaches 30 seconds. As previously mentioned, the FDI performance is evaluated based on the minimum sensor/actuator bias magnitude which can be isolated, and the accuracy of health parameter estimates. The smaller the minimum bias that can be isolated, the better the performance of the FDI system is considered to be. However, if the minimum bias becomes too small relative to sensor noise, the assumption that one sensor or actuator may be biased at a time may no longer hold since multiple sensors and actuators may contain small biases in the real engine environment. Therefore, it is undesirable to have an FDI system which is overly sensitive to small sensor or actuator bias. For health parameter estimation, the performance is considered acceptable if the average estimation error (difference) is less than $0.5 \%$.

1) Nominal Performance: Baseline Condition \#1. Table 6 shows performance evaluation results when the FDI system is applied to the nonlinear simulation at baseline condition \#1. For each of the eight simulation scenarios, a bias was injected into one of the sensors or actuators, and then the bias with the smallest magnitude that could be isolated by the FDI system was determined. The isolated minimum positive bias shown in the table is in \% of trim value of the nominal baseline condition. It is desirable to normalize the bias by full-scale values in addition to trim values. However, full-scale values for this engine model are currently not available. The numbers in parentheses indicate the Euclidian distance (square root of sum of squares) of four health parameter estimation errors, each of which was averaged over the last 50 seconds of the simulation. The entries that correspond to cases where at least one health parameter estimation absolute error was larger than or equal to $0.5 \%$ are shaded. It should be noted that the health parameter estimation accuracy of each of the eight sensor FDI filters is independent of a bias in the corresponding sensor. No false alarms were generated on any simulation scenario with sensor/actuator bias (88 cases) or without sensor/actuator bias (8 scenarios).

From Table 6, it is observed that the magnitude of the minimum isolated bias for individual sensors and actuators varies slightly with the simulation scenario. However, apparent variations in bias magnitude can be observed between different sensors and actuators. For instance, the bias in the XN25 sensor can be isolated at low magnitude while the minimum bias that can be isolated in the A16 actuator is quite large. The performance variations among the FDI filters are considered to be mainly due to the uniqueness of the information provided by the sensors and actuators. During the course of the performance evaluation, it was found that the following pairs of FDI filters were difficult to isolate from each other: T56 and WF36, PS15 and A16, and PS56 and A8. Particularly, in the cases where either PS15 or A16 is biased, the two FDI filters focused on these

Table 6. Performance of the FDI System Applied to Nonlinear Simulation at Baseline Condition \#1

\begin{tabular}{|c|c|c|c|c|c|c|c|c|c|c|c|}
\hline \multirow{2}{*}{ 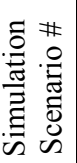 } & \multicolumn{11}{|c|}{$\begin{array}{l}\text { Isolated Minimum Positive Bias in \% of Nominal Trim Value } \\
\text { (Euclidian distance of health parameter estimation errors in parentheses) }\end{array}$} \\
\hline & XN2 & $\mathrm{XN} 25$ & $\mathrm{~T} 27 \mathrm{D}$ & T56 & PS15 & P27 & PS3 & PS56 & WF36 & A8 & A16 \\
\hline 1 & $\begin{array}{c}3.3 \\
(0.11)\end{array}$ & $\begin{array}{c}0.9 \\
(0.01)\end{array}$ & $\begin{array}{c}1.4 \\
(0.03)\end{array}$ & $\begin{array}{c}2.8 \\
(0.03)\end{array}$ & $\begin{array}{c}12.1 \\
(0.07)\end{array}$ & $\begin{array}{c}3.2 \\
(0.01)\end{array}$ & $\begin{array}{c}1.4 \\
(0.01)\end{array}$ & $\begin{array}{c}4.8 \\
(0.05)\end{array}$ & $\begin{array}{c}2.6 \\
(0.01)\end{array}$ & $\begin{array}{c}5.6 \\
(0.06)\end{array}$ & $\begin{array}{c}25.1 \\
(0.02)\end{array}$ \\
\hline 2 & $\begin{array}{c}3.3 \\
(0.23)\end{array}$ & $\begin{array}{c}1.1 \\
(0.19)\end{array}$ & $\begin{array}{l}1.3 \\
(0.17)\end{array}$ & $\begin{array}{c}2.4 \\
(0.19)\end{array}$ & $\begin{array}{l}12.1 \\
(0.20)\end{array}$ & $\begin{array}{c}3.9 \\
(0.23)\end{array}$ & $\begin{array}{l}1.5 \\
(0.16)\end{array}$ & $\begin{array}{c}4.7 \\
(0.21)\end{array}$ & $\begin{array}{c}3.2 \\
(0.19)\end{array}$ & $\begin{array}{c}6.0 \\
(0.19)\end{array}$ & $\begin{array}{c}32.3 \\
(0.18)\end{array}$ \\
\hline 3 & $\begin{array}{c}3.6 \\
(0.27)\end{array}$ & $\begin{array}{c}1.1 \\
(0.32)\end{array}$ & $\begin{array}{c}1.3 \\
(0.34)\end{array}$ & $\begin{array}{c}2.6 \\
(0.33)\end{array}$ & $\begin{array}{c}10.2 \\
(0.34)\end{array}$ & $\begin{array}{c}3.5 \\
(0.32)\end{array}$ & $\begin{array}{l}1.5 \\
(0.36)\end{array}$ & $\begin{array}{c}4.2 \\
(0.35)\end{array}$ & $\begin{array}{c}3.1 \\
(0.34)\end{array}$ & $\begin{array}{c}5.5 \\
(0.34)\end{array}$ & $\begin{array}{c}34.9 \\
(0.33)\end{array}$ \\
\hline 4 & $\begin{array}{c}3.5 \\
(0.35)\end{array}$ & $\begin{array}{c}1.3 \\
(0.21)\end{array}$ & $\begin{array}{c}1.3 \\
(0.21)\end{array}$ & $\begin{array}{c}2.9 \\
(0.22)\end{array}$ & $\begin{array}{c}9.7 \\
(0.21)\end{array}$ & $\begin{array}{c}3.7 \\
(0.22)\end{array}$ & $\begin{array}{c}1.3 \\
(0.23)\end{array}$ & $\begin{array}{c}3.5 \\
(0.25)\end{array}$ & $\begin{array}{c}3.1 \\
(0.19)\end{array}$ & $\begin{array}{c}5.3 \\
(0.26)\end{array}$ & $\begin{array}{c}32.8 \\
(0.18)\end{array}$ \\
\hline 5 & $\begin{array}{c}2.8 \\
(0.49)\end{array}$ & $\begin{array}{c}0.9 \\
(0.58)\end{array}$ & $\begin{array}{c}1.2 \\
(0.59)\end{array}$ & $\begin{array}{c}2.1 \\
(0.59)\end{array}$ & $\begin{array}{c}9.7 \\
(0.58)\end{array}$ & $\begin{array}{c}3.9 \\
(0.60)\end{array}$ & $\begin{array}{c}1.3 \\
(0.58)\end{array}$ & $\begin{array}{c}3.5 \\
(0.57)\end{array}$ & $\begin{array}{c}2.4 \\
(0.60)\end{array}$ & $\begin{array}{c}5.8 \\
(0.62)\end{array}$ & $\begin{array}{c}25.1 \\
(0.59)\end{array}$ \\
\hline 6 & $\begin{array}{c}2.8 \\
(0.70)\end{array}$ & $\begin{array}{c}0.9 \\
(0.47)\end{array}$ & $\begin{array}{c}1.1 \\
(0.47)\end{array}$ & $\begin{array}{c}2.1 \\
(0.48)\end{array}$ & $\begin{array}{c}10.1 \\
(0.47)\end{array}$ & $\begin{array}{c}3.8 \\
(0.53)\end{array}$ & $\begin{array}{c}1.3 \\
(0.46)\end{array}$ & $\begin{array}{c}3.5 \\
(0.46)\end{array}$ & $\begin{array}{c}2.7 \\
(0.46)\end{array}$ & $\begin{array}{c}5.7 \\
(0.50)\end{array}$ & $\begin{array}{c}25.6 \\
(0.47)\end{array}$ \\
\hline 7 & $\begin{array}{c}3.4 \\
(0.76)\end{array}$ & $\begin{array}{c}1.1 \\
(0.77)\end{array}$ & $\begin{array}{c}1.4 \\
(0.78)\end{array}$ & $\begin{array}{c}2.6 \\
(0.78)\end{array}$ & $\begin{array}{c}11.9 \\
(0.76)\end{array}$ & $\begin{array}{c}3.1 \\
(0.82)\end{array}$ & $\begin{array}{c}1.4 \\
(0.79)\end{array}$ & $\begin{array}{c}4.2 \\
(0.80)\end{array}$ & $\begin{array}{c}2.9 \\
(0.80)\end{array}$ & $\begin{array}{c}5.9 \\
(0.86)\end{array}$ & $\begin{array}{c}30.1 \\
(0.77)\end{array}$ \\
\hline 8 & $\begin{array}{c}3.3 \\
(0.86)\end{array}$ & $\begin{array}{c}1.1 \\
(0.66)\end{array}$ & $\begin{array}{c}1.3 \\
(0.65)\end{array}$ & $\begin{array}{c}2.6 \\
(0.66)\end{array}$ & $\begin{array}{c}11.8 \\
(0.65)\end{array}$ & $\begin{array}{c}3.1 \\
(0.77)\end{array}$ & $\begin{array}{c}1.4 \\
(0.66)\end{array}$ & $\begin{array}{c}4.2 \\
(0.68)\end{array}$ & $\begin{array}{c}3.0 \\
(0.68)\end{array}$ & $\begin{array}{c}5.9 \\
(0.71)\end{array}$ & $\begin{array}{c}30.4 \\
(0.65)\end{array}$ \\
\hline
\end{tabular}


parameters retain low fault indicator signals until the bias magnitude becomes very large (see Table 6). A possible approach to handle such a problem is to utilize additional information, besides the sensor estimation error, in the fault decision making process. Although two filters generate small sensor estimation errors, it was found that the "wrong" filter usually generates health parameter estimates that are beyond the expected linear range. For instance, in scenario \#1, all FDI filters except for the PS15 and A16 filters exceed the detection threshold when the bias in PS15 is $1.5 \%$. With this bias magnitude, the two filters retain low residuals; however, the A16 filter generates a health parameter estimate above $5.0 \%$, which is considered well beyond the linear range. By putting some bounds on health parameter estimates, any filter which generates estimated values beyond those bounds could be penalized when the fault indicator signal is computed.

The difficulty of accurately estimating health parameters increases as the magnitude of the step perturbation in these parameters (component fault) increases. For most of the FDI filters, the health parameter estimates are acceptable except for scenario 7. Scenario 7 can be considered a borderline case where the estimation performance of the FDI filters starts to deviate from the acceptable level. FDI filter \#1 (XN2) generates at least one health parameter estimation absolute error above $0.5 \%$ in scenarios 6 and 8 . The low-spool speed provides essential information for estimating health parameters; therefore the cases where the XN2 sensor is biased are very challenging in terms of obtaining accurate estimation of health parameters.

2) FDI Performance Recovery: Baseline Condition \#2. Table 7 shows performance evaluation results when the FDI system is applied to the nonlinear simulation at baseline condition \#2. As discussed earlier, the trim value data is updated based on the new baseline condition so that the initial steady-state mismatch is eliminated. No false alarms were generated on any simulation scenario with sensor/actuator bias $(88$ cases $)$ or without sensor/actuator bias ( 8 scenarios).

It can be observed that the magnitude of the minimum isolated bias is very close to the previous case, indicating that the loss of sensor/actuator FDI performance due to mismatch in the baseline condition can be recovered by updating the trim value data. However, the accuracy of health parameter estimation is not recovered. The estimation errors become very large when health parameter step perturbations exceed $2 \%$ (scenarios 5 through 8 ). Although the initial steady-state values were made to match, the new steady-state values after the perturbations do not match because of the difference in the dynamics (specifically, steady-state gain) between the nonlinear simulation and the FDI system. This difference is causing the health parameter estimation errors. As discussed before, when there is a mismatch in the steady-state condition, the mismatch is "smeared" to the four health parameters being estimated. Thus, the four health parameters may no longer represent the actual health parameters. Instead, they become "tuning" parameters. A Kalman filter tunes these four health parameters so that its sensor estimates will match with the outputs of the nonlinear simulation.

As seen in this example, large health parameter estimation errors do not necessarily result in large sensor estimation errors. Therefore, determining the confidence in estimated health parameters, which is currently based on sensor estimation errors, is always a challenging issue in the health estimation problem. With the current FDI design, component faults can be inferred from changes in the estimated health parameters; however, the corresponding damage level cannot be estimated accurately. As mentioned previously, one possible approach to improve the estimation accuracy is to update the bank of Kalman filters based on the baseline degradation.

\section{Evaluation Summary}

The FDI system was also evaluated for negative biases in each sensor and actuator. The results were very similar to the positive bias cases in terms of the minimum magnitude of isolated biases and health parameter estimation accuracy. Again, the FDI system successfully isolated sensor and actuator faults without generating false alarms for all simulation cases. In a total of 368 simulation fault cases (176 cases for each bias direction and 16 no-bias cases) investigated in this paper, no false alarm was generated.

Table 7. Performance of the FDI System Applied to Nonlinear Simulation at Baseline Condition \#2

\begin{tabular}{|c|c|c|c|c|c|c|c|c|c|c|c|}
\hline \multirow{2}{*}{ 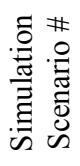 } & \multicolumn{11}{|c|}{$\begin{array}{l}\text { Isolated Minimum Positive Bias in \% of Nominal Trim Value } \\
\text { (Euclidian distance of health parameter estimation errors in parentheses) }\end{array}$} \\
\hline & XN2 & XN25 & $\mathrm{T} 27 \mathrm{D}$ & T56 & PS15 & P27 & PS3 & PS56 & WF36 & A8 & A16 \\
\hline 1 & $\begin{array}{c}3.5 \\
(0.14)\end{array}$ & $\begin{array}{c}0.8 \\
(0.01)\end{array}$ & $\begin{array}{c}1.4 \\
(0.03)\end{array}$ & $\begin{array}{c}2.8 \\
(0.03)\end{array}$ & $\begin{array}{c}11.6 \\
(0.07)\end{array}$ & $\begin{array}{c}3.2 \\
(0.01)\end{array}$ & $\begin{array}{c}1.4 \\
(0.01)\end{array}$ & $\begin{array}{c}4.8 \\
(0.05)\end{array}$ & $\begin{array}{c}2.6 \\
(0.01)\end{array}$ & $\begin{array}{c}5.5 \\
(0.04)\end{array}$ & $\begin{array}{c}25.1 \\
(0.02)\end{array}$ \\
\hline 2 & $\begin{array}{c}3.5 \\
(0.83)\end{array}$ & $\begin{array}{c}1.1 \\
(0.41)\end{array}$ & $\begin{array}{c}1.4 \\
(0.43)\end{array}$ & $\begin{array}{c}2.5 \\
(0.34)\end{array}$ & $\begin{array}{c}13.2 \\
(0.38)\end{array}$ & $\begin{array}{c}3.7 \\
(0.37)\end{array}$ & $\begin{array}{c}1.5 \\
(0.40)\end{array}$ & $\begin{array}{c}4.2 \\
(0.41)\end{array}$ & $\begin{array}{c}2.9 \\
(0.45)\end{array}$ & $\begin{array}{c}6.7 \\
(0.41)\end{array}$ & $\begin{array}{c}29.2 \\
(0.41) \\
\end{array}$ \\
\hline 3 & $\begin{array}{c}3.1 \\
(0.55)\end{array}$ & $\begin{array}{c}0.9 \\
(0.68) \\
\end{array}$ & $\begin{array}{c}1.2 \\
(0.68)\end{array}$ & $\begin{array}{c}2.2 \\
(0.68)\end{array}$ & $\begin{array}{c}11.3 \\
(0.70) \\
\end{array}$ & $\begin{array}{c}3.3 \\
(0.62) \\
\end{array}$ & $\begin{array}{c}1.5 \\
(0.72)\end{array}$ & $\begin{array}{c}4.2 \\
(0.70) \\
\end{array}$ & $\begin{array}{c}3.0 \\
(0.68) \\
\end{array}$ & $\begin{array}{c}5.8 \\
(0.69) \\
\end{array}$ & $\begin{array}{c}32.0 \\
(0.67) \\
\end{array}$ \\
\hline 4 & $\begin{array}{c}3.5 \\
(0.41)\end{array}$ & $\begin{array}{c}1.0 \\
(0.60)\end{array}$ & $\begin{array}{c}1.4 \\
(0.64)\end{array}$ & $\begin{array}{c}2.1 \\
(0.61)\end{array}$ & $\begin{array}{c}11.4 \\
(0.60)\end{array}$ & $\begin{array}{c}3.4 \\
(0.34)\end{array}$ & $\begin{array}{c}1.5 \\
(0.63)\end{array}$ & $\begin{array}{c}4.2 \\
(0.63)\end{array}$ & $\begin{array}{c}3.1 \\
(0.61)\end{array}$ & $\begin{array}{c}5.2 \\
(0.59)\end{array}$ & $\begin{array}{c}31.4 \\
(0.59)\end{array}$ \\
\hline 5 & $\begin{array}{c}3.0 \\
(1.29)\end{array}$ & $\begin{array}{c}0.9 \\
(1.30)\end{array}$ & $\begin{array}{c}1.1 \\
(1.30)\end{array}$ & $\begin{array}{c}2.4 \\
(1.28)\end{array}$ & $\begin{array}{c}9.9 \\
(1.26)\end{array}$ & $\begin{array}{c}3.6 \\
(1.19)\end{array}$ & $\begin{array}{c}1.4 \\
(1.33)\end{array}$ & $\begin{array}{c}3.8 \\
(1.30)\end{array}$ & $\begin{array}{c}2.6 \\
(1.34)\end{array}$ & $\begin{array}{c}4.8 \\
(1.32)\end{array}$ & $\begin{array}{c}27.0 \\
(1.28)\end{array}$ \\
\hline 6 & $\begin{array}{c}3.1 \\
(0.44)\end{array}$ & $\begin{array}{c}1.0 \\
(1.19)\end{array}$ & $\begin{array}{c}1.1 \\
(1.23)\end{array}$ & $\begin{array}{c}2.2 \\
(1.19)\end{array}$ & $\begin{array}{c}9.9 \\
(1.18)\end{array}$ & $\begin{array}{c}3.7 \\
(0.95)\end{array}$ & $\begin{array}{c}1.4 \\
(1.22)\end{array}$ & $\begin{array}{c}3.9 \\
(1.20)\end{array}$ & $\begin{array}{c}2.9 \\
(1.20)\end{array}$ & $\begin{array}{c}4.8 \\
(1.19)\end{array}$ & $\begin{array}{c}26.6 \\
(1.21) \\
\end{array}$ \\
\hline 7 & $\begin{array}{c}3.6 \\
(2.11)\end{array}$ & $\begin{array}{c}1.0 \\
(1.89)\end{array}$ & $\begin{array}{c}1.3 \\
(1.88)\end{array}$ & $\begin{array}{c}2.8 \\
(1.85)\end{array}$ & $\begin{array}{c}11.3 \\
(1.87)\end{array}$ & $\begin{array}{c}3.2 \\
(1.74)\end{array}$ & $\begin{array}{c}1.4 \\
(1.91)\end{array}$ & $\begin{array}{c}4.6 \\
(1.88) \\
\end{array}$ & $\begin{array}{c}3.1 \\
(1.92)\end{array}$ & $\begin{array}{c}5.9 \\
(1.94) \\
\end{array}$ & $\begin{array}{c}34.3 \\
(1.84) \\
\end{array}$ \\
\hline 8 & $\begin{array}{c}3.6 \\
(1.14)\end{array}$ & $\begin{array}{c}1.1 \\
(1.79)\end{array}$ & $\begin{array}{c}1.4 \\
(1.82)\end{array}$ & $\begin{array}{c}2.6 \\
(1.78)\end{array}$ & $\begin{array}{c}11.5 \\
(1.79)\end{array}$ & $\begin{array}{c}3.1 \\
(1.54)\end{array}$ & $\begin{array}{c}1.4 \\
(1.81)\end{array}$ & $\begin{array}{c}4.3 \\
(1.76)\end{array}$ & $\begin{array}{c}3.0 \\
(1.81)\end{array}$ & $\begin{array}{c}6.2 \\
(1.77)\end{array}$ & $\begin{array}{c}33.8 \\
(1.79)\end{array}$ \\
\hline
\end{tabular}




\section{CONCLUSIONS}

An approach utilizing a bank of Kalman filters with an augmented state vector was developed for detection and isolation of sensor and actuator faults in conjunction with the detection of component faults. This methodology was applied to an aircraft engine simulation and demonstrated the capability to successfully detect and isolate sensor and actuator bias errors even in the presence of engine component faults caused by incidents such as foreign object damage (FOD). An approach to maintain the robustness of the fault detection and isolation (FDI) system even in the presence of engine baseline degradation was presented. This approach was demonstrated through an example where the FDI system was applied to the nonlinear engine simulation at a degraded baseline condition. Since the bank of Kalman filters was designed based on the healthy (nominal) baseline condition, the baseline degradation of the engine simulation caused mismatches in both the initial steady-state condition and the dynamics. The initial steady-state mismatch was eliminated by updating the trim value data. In the presence of errors due to mismatched model dynamics, the Kalman filters used the four health parameters as "tuners" so that sensor estimates matched the outputs of the degraded engine simulation. Health parameter estimation errors became large because of this "tuning" effect; however, low sensor estimation errors were retained, and as a result, no false alarms were generated.

For further improvement of the FDI system, the process to improve the accuracy of health parameter estimation in the presence of engine baseline degradation needs to be investigated. In future work, the above issue will be considered in addition to extending the FDI capability over a wider flight region and applying the FDI design methodology to other types of faults.

\section{REFERENCES}

[1] Frank, P.M., 1990, "Fault Diagnosis in Dynamic Systems Using Analytical and Knowledge-based Redundancy-A Survey and Some New Results," Automatica, 26, pp. 459-474.

[2] Patton, R.J., and Chen, J., 1992 "Robust Fault Detection of Jet Engine Sensor Systems Using Eigenstructure Assignment," Journal of Guidance, Control, and Dynamics, 15, pp. 1491-1497.

[3] Merrington, G., Kwon, O.-K., Goodwin, G., and Carlsson, B., 1991, "Fault Detection and Diagnosis in Gas Turbines," Journal of Engineering for Gas Turbines and Power, 113, pp. 276-282.

[4] Volponi, A. J, DePold, H., Ganguli, R., and Chen D., 2000, "The Use of Kalman Filter and Neural Network Methodologies in Gas Turbine Performance Diagnostics: A Comparative Study," ASME Paper 2000-GT-547, Proceedings of ASME TURBOEXPO 2000, Munich, Germany.

[5] Merrill, W.C., DeLaat, J.C., and Bruton, W.M., 1988, “Advanced Detection, Isolation, and Accommodation of Sensor Failures-RealTime Evaluation," Journal of Guidance, Control, and Dynamics, 11, pp. 517-526.

[6] Duyar, A., Eldem, V., Merrill, W., and Guo, T.-H., 1994, "Fault Detection and Diagnosis in Propulsion Systems: A Fault Parameter Estimation Approach," Journal of Guidance, Control, and Dynamics, 17, pp. 104-108.
[7] Menke, T.E., and Maybeck, P.S., 1995, "Sensor/Actuator Failure Detection in the Vista F-16 by Multiple Model Adaptive Estimation," IEEE Transactions on Aerospace and Electronic Systems, 31, pp. 1218-1229.

[8] Lambert, H.H., 1991, "A Simulation Study of Turbofan Engine Deterioration Estimation Using Kalman Filtering Techniques," NASA TM-104233.

[9] España, M.D., 1993, “On the Estimation Algorithm for Adaptive Performance Optimization of Turbofan Engines," Paper AIAA-931823, AIAA/ASME/SAE/ASEE $29^{\text {th }}$ Joint Propulsion Conference, Monterey, CA.

[10] Adibhatla, S., and Lewis, T.J., 1997, "Model-Based Intelligent Digital Engine Control (MoBIDEC)," Paper AIAA-97-3192, AIAA/ASME/SAE/ASEE $33^{\text {rd }}$ Joint Propulsion Conference, Seattle, WA.

[11] Lu, P.-J., Zhang, M.-C., Hsu, T.-C., and Zhang, J., 2001, “An Evaluation of Engine Faults Diagnostics Using Artificial Neural Networks," Journal of Engineering for Gas Turbines and Power, 123, pp. 340-346.

[12] Pinelli, M., and Spina, P.R., 2002, "Gas Turbine Field Performance Determination: Sources of Uncertainties," Journal of Engineering for Gas Turbines and Power, 124, pp. 155-160.

[13] Kerr, L.J., Nemec, T.S., and Gallops, G.W., 1991, "Real-Time Estimation of Gas Turbine Engine Damage Using a Control Based Kalman Filter Algorithm," ASME Paper 91-GT-216, International Gas Turbine and Aeroengine Congress and Exposition, Orlando, FL.

[14] Lakshminarasimha, A.N., Boyce, M.P., and Meher-Homji, C.B., 1994, "Modeling and Analysis of Gas Turbine Performance Deterioration," Journal of Engineering for Gas Turbines and Power, 116, pp. 46-52.

[15] Luppold, R.H., Roman, J.R., Gallops, G.W., and Kerr, L.J., 1989, "Estimating In-Flight Engine Performance Variations Using Kalman Filter Concepts," Paper AIAA-89-2584, AIAA/ASME/SAE/ASEE $25^{\text {th }}$ Joint Propulsion Conference, Monterey, CA.

[16] Kobayashi, T., and Simon, D.L., 2001, "A Hybrid Neural Network-Genetic Algorithm Technique for Aircraft Engine Performance Diagnostics," Paper AIAA-2001-3763, AIAA/ASME/SAE/ASEE $37^{\text {th }}$ Joint Propulsion Conference, Salt Lake City, UT.

[17] Volponi, A.J., 1994, "Sensor Error Compensation in Engine Performance Diagnostics," ASME Paper 94-GT-58, International Gas Turbine and Aeroengine Congress and Exposition, The Hague, Netherlands. 


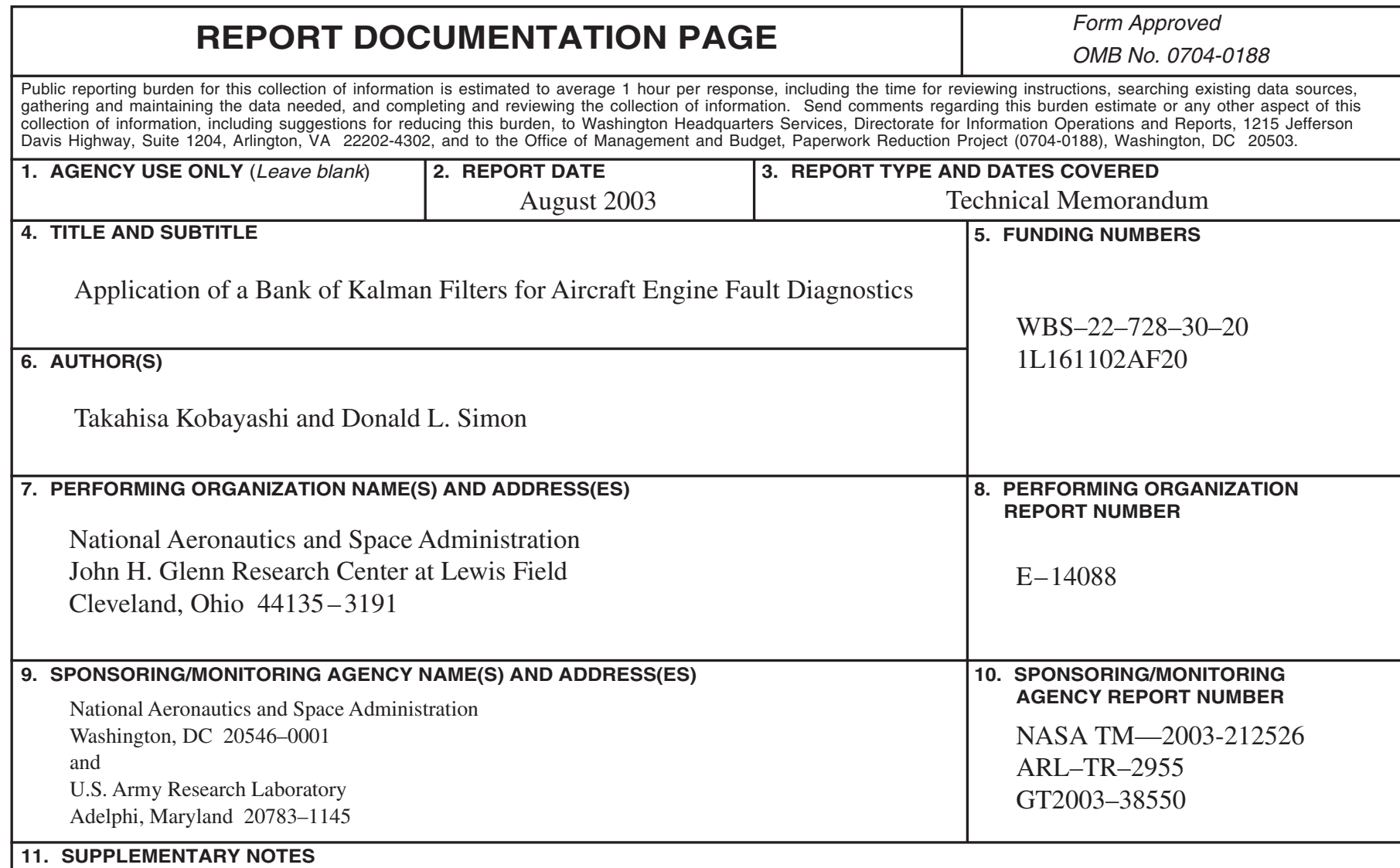

\section{SUPPLEMENTARY NOTES}

Prepared for the Turbo Expo 2003 cosponsored by the American Society of Mechanical Engineers and the International Gas Turbine Institute, Atlanta, Georgia, June 16-19, 2003. Takahisa Kobayashi, QSS Group, Inc., Cleveland, Ohio 44135; and Donald L. Simon, U.S. Army Research Laboratory, NASA Glenn Research Center. Responsible person, Donald L. Simon, organization code 0300, 216-433-3740.

12a. DISTRIBUTION/AVAILABILITY STATEMENT 12b. DISTRIBUTION CODE

Unclassified - Unlimited

Subject Category: 07

Distribution: Nonstandard

Available electronically at http://gltrs.grc.nasa.gov

This publication is available from the NASA Center for AeroSpace Information, 301-621-0390.

13. ABSTRACT (Maximum 200 words)

In this paper, a bank of Kalman filters is applied to aircraft gas turbine engine sensor and actuator fault detection and isolation (FDI) in conjunction with the detection of component faults. This approach uses multiple Kalman filters, each of which is designed for detecting a specific sensor or actuator fault. In the event that a fault does occur, all filters except the one using the correct hypothesis will produce large estimation errors, thereby isolating the specific fault. In the meantime, a set of parameters that indicate engine component performance is estimated for the detection of abrupt degradation. The proposed FDI approach is applied to a nonlinear engine simulation at nominal and aged conditions, and the evaluation results for various engine faults at cruise operating conditions are given. The ability of the proposed approach to reliably detect and isolate sensor and actuator faults is demonstrated.

\section{SUBJECT TERMS}

Aircraft engines; Systems health monitoring; Gas turbine engines; Flight safety 15. NUMBER OF PAGES 16

\begin{tabular}{|c|c|c|}
\hline $\begin{array}{c}\text { 17. SECURITY CLASSIFICATION } \\
\text { OF REPORT } \\
\text { Unclassified }\end{array}$ & $\begin{array}{c}\text { 18. SECURITY CLASSIFICATION } \\
\text { OF THIS PAGE } \\
\text { Unclassified }\end{array}$ & $\begin{array}{c}\text { 19. SECURITY CLASSIFICATION } \\
\text { OF ABSTRACT } \\
\text { Unclassified }\end{array}$ \\
\hline
\end{tabular}

